\title{
O Empreendedorismo Cultural no Cinema sob o Olhar Discursivo da Ação do Produtor de Filmes em Pernambuco \\ (1)
}

José Roberto Ferreira Guerra ${ }^{1}$

Fernando Paiva Júnior ${ }^{1}$

Chris Herbert Berenguer Pereira ${ }^{2}$

\footnotetext{
${ }^{1}$ Universidade Federal de Pernambuco - UFPE

${ }^{2}$ Centro de Ciências Sociais Aplicadas / UNIVERSIDADE DE PERNAMBUCO
} 


\title{
O Empreendedorismo Cultural no Cinema sob o Olhar Discursivo da Ação do Produtor de Filmes em Pernambuco
}

\begin{abstract}
Resumo
O empreendedorismo cultural é um fenômeno multidimensional que revela peculiaridades dos produtores culturais repercutidas na elaboração de bens simbólicos com valor artístico e sua ação se repercute para além de uma produção empreendedora clássica. Bens simbólicos são configurados na representação de identidades que emergem em polos de fora do mainstream da produção midiática brasileiro. Nesse sentido, o empreendedor cultural no campo da produção de filmes em Pernambuco assinala o significado produção fílmica da região. $\mathrm{O}$ corpus contempla entrevistas abertas com seis produtores de cinema locais, tratado com o suporte da análise do discurso. O Empreendedorismo Cultural no âmbito da geração de capital social se fortalece pelo relacionamentos humanos e a superação do viés economicista hegemônico em que a posição do produtor cultural é demarcada por seu papel articulador na produção dos filmes.
\end{abstract}

Palavras-chave: Empreendedorismo Cultural. Produtor de Cinema. Cinema de Pernambuco. Análise do Discurso.

\section{Introdução}

Transformações culturais, econômicas, políticas e sociais da contemporaneidade não mais caracterizam o sistema de produção capitalista em sua concepção original, uma vez que culminam em um sistema no qual aspectos estéticos e artísticos são anexados às mercadorias capitalistas na busca pela criação de valor simbólico (RAVASSI e RINDOVA, 2013). Diante das mudanças estruturais que alteraram os rumos da economia ao longo das últimas décadas do século passado, o empreendedorismo vêm despertando o interesse de órgãos públicos, da iniciativa privada, do terceiro setor, de entidades paraestatais e da academia. No ambiente científico, a busca por uma definição do termo empreendedorismo pela da ação do empreendedor têm sido problemáticas no que se refere ao esforço por possibilidades plausíveis de teorização (JULIEN, 2010; GUERRA e PAIVA JÚNIOR, 2014; ORIHUELAGALLARDO et al, 2018).

Calás et al. (2009) alertam para a ampliação do foco de discussão acerca do Empreendedorismo e asseguram que possam ser instituídos estudos críticos sobre o tema (Critical Entrepreneurship Studies - CES). Assim, Davel e Cora (2017) indicam o avanço do tema para a análise da criação de valor social, cultural e artístico. O estudo de Ellmeier (2007) aponta para o avanço do empreendedorismo no campo da cultura, compreendido pela análise de novas formas contratuais de trabalho e articulação dos profissionais da área cultural em torno de práticas de gestão. Logo, as novas abordagens contribuem para a ampliação da discussão acerca da ação do empreendedor cultural, ancorada em um processo interativo que media a troca de recursos, possibilita a aquisição de capitais e potencializa a geração de riqueza (SMITS, 2016).

O flanco teórico e analítico presente no establishment da área do Empreendedorismo demanda uma definição plausível para o fenômeno Empreendedorismo cultural (BANKS et 
al., 2000). Para os autores, o empreendedorismo cultural é aquele que se vincula com a produção de bens e serviços culturais, resultando na elaboração de artefatos com cujo principal valor é o simbólico (BANKS et al, 2000). Tal acepção aproxima a gramática do Empreendedorismo de conceitos advindos do campo da cultura, a considerar aqueles que remetem a símbolos e signos. Além disso, o Empreendedorismo cultural é caracterizado como cerne de inovação, flexibilidade, orientação para ideias criativas e confluência do local com o global (BELTRÁN; MIGUEL, 2014; SUNG, 2015; GUNDOLF, JOAUEN e GAST, 2018).

Os empreendedores culturais compartilham características comuns aos empreendedores preconizados pelas teorias clássicas sobre o tema, a exemplo do que sugerem Schumpeter (1982) e Drucker (2008). Tais estudos registram que eles promovem práticas inovadoras, criando novos produtos e gerando novos mercados. No entanto, essas obras revelam diferenças significativas a respeito do empreendedor, a exemplo da percepção do risco econômico reduzido em que incorrem. No que tange ao empreendedorismo no universo da cultura, os investimentos direcionados para a produção cultural estão centrados na potencialização do capital simbólico de projetos artísticos (PELTRONIEMI, 2015) ou suportados por políticas culturais de fomento (BERTELLI et al, 2014).

Klamer (2011) apresenta o empreendedor cultural como aquele dirigente direcionado para a produção de bens com alto valor cultural que encara de frente a estrutura econômica e se utiliza de um formato da gestão voltado para projetos. Logo, tal empreendedor desenvolve tarefas que realçam a produção de valor cultural para produtores e consumidores (LAMPEL e GERMAIN, 2016), orientadas para estratégias de identidade artística e produtor junto à reputação criativa (SCOTT, 2012). Dessa forma, a pergunta central do estudo é: como ocorre o Empreendedorismo Cultural no campo da produção de filmes em Pernambuco?

\section{A agência do Empreendedorismo cultural}

Em um cenário organizacional no qual as atividades relacionadas à criatividade passam a compor políticas públicas de desenvolvimento regional (HERÁUD, 2016), emerge o Empreendedorismo cultural caracterizado pela produção com valor não-utilitário e alto nível de significado estético (PELTRONIEMI, 2015). Esse fenômeno se conecta à economia informacional pós-industrial pautada pela aceitação do risco e por redes sociais movidas pela confiança e cooperação entre seus membros, num cenário da produção pós-fordista (JULIEN, 2010). Aqui agentes e agências colaboram na busca por novas ideias em torno dos bens culturais (ROCHA et al, 2018). Nesse contexto, a ação empreendedora se associa a um perfil reflexivo de atuação do empreendedor, dotado de competências de construção veloz de contextos e observador tanto das oportunidades do ambiente externo, quanto otimizador dos recursos disponíveis no ambiente interno da sua organização (FLETCHER, 2006). Eles driblam etapas convencionais da tomada de decisão e desenvolvem ações intuitivas e inovadoras, engendrando novas formas de organização relacionadas a circunstâncias pessoais dirigidas para o ato de empreender (trajetória pessoal) e características do seu macro ou micro ambiente (contexto sócio-histórico) (GUERRA; PAIVA JÚNIOR, 2011, 2014).

Os empreendimentos desenvolvidos pelos empreendedores culturais estão imersos em milieux, redes e clusters que contemplam o intercâmbio de conhecimentos e experiências (JULIEN, 2010; BANKS et al., 2000; BERTELLI et al, 2014). Klamer (2011) define o 
empreendedor cultural como agente que encara a estrutura econômica e se utiliza do formato da gestão de projetos como instrumento para a criação de valor (MOON e SONG, 2015), uma vez que eles são orientados para o empreendimento relacionado a sua identificação como artista/produtor e fortalecimento da sua reputação criativa (SCOTT, 2012; ORIHUELAGALLARDO et al, 2018).

A assimilação das inovações tecnológicas pela via inclusiva exprime a tecnologia social que reverte certas consequências precarizadoras do capitalismo. Logo, a produção cultural desvela a busca por uma agência empreendedora numa produção pautada pela inserção de grupos profissionais periféricos e favorece a (re)construção contínua de identidades pela cooperação entre os pares.

\section{O contexto histórico do cinema produzido em Pernambuco}

O cinema em Pernambuco conheceu ciclos de produção cinematográfica que colocaram o Estado como um dos mais importantes polos produtores do país. Nos anos vinte, o "Ciclo do Recife" gerou visibilidade para a produção local e "além de ter sido o primeiro grande movimento cinematográfico na história do cinema pernambucano, foi o mais produtivo dos ciclos regionais do início do século XX no Brasil" (CUNHA FILHO, 2006, p. 7). Durante esse período, foram produzidos ao todo 33 filmes que contribuíram para a constituição de um ciclo de produção descentralizado geograficamente (CUNHA FILHO, 2010). Durante a fase do "Ciclo do Recife", começou a surgir um grande número de salas de cinema na cidade. O público dessa produção se orgulhava de assistir os filmes produzidos na própria "terra". Apesar das precárias condições técnicas e econômicas da época, filmes como "Aitaré da Praia" (1925, diretor Gentil Roiz) alcançaram destaque local. O contexto desse ciclo se alinha ao estilo da produção internacional, tanto que Recife passa a ter o status da Hollywood nordestina.

Já nas décadas de 1970 e 1980, os filmes em "super 8" obtiveram grande êxito nos festivais de curtas-metragens criados no Brasil (CARVALHO, 2006; FIGUEIRÔA, 2000). Essa geração de realizadores fílmicos compartilhou uma "estrutura de cooperação" que possibilitou a união de pessoas for por afinidade para a produção de filmes (NOGUEIRA, 2009). Durante esse período, cerca de 200 filmes de culta e longa metragem foram produzidos (FIGUEIRÔA, 2000). Títulos como "Valente é o Galo" (1974, diretor Fernando Spencer), "O Palhaço Degolado" (1976, diretor Jomar Muniz de Brito) e "Esses Onze Aí" (1978, diretores Geneton Moraes Neto e Paulo Cunha) são emblemáticos desse ciclo. Cunha Filho (2010) diz que o Recife se reconheceu na tela naquela época.Nos anos noventa, o movimento Manguebeat [re]conecta a produção artística pernambucana aos meios de comunicação de massa. A produção contemporânea de filmes pernambucanos de longa-metragem tem como marco zero o filme "Baile Perfumado" (1996, diretores Lírio Ferreira e Paulo Caldas). O Árido Movie, movimento atual, tem como influência o manguebeat musical (FIGUEIRÔA, 2006), produção de filmes marcados pela "brodagem"1 - brotherhood (GUERRA; PAIVA JÚNIOR, 2011).

1 Brodagem é um neologismo que demonstra o espírito de coletividade que permeia o grupo de realizadores, "configura uma tecnologia social de gestão ancorada na cooperação e na confiança" (GUERRA, PAIVA JÚNIOR, 2011, p. 89). 
O movimento atual é formado por um grupo que criou filmes com reflexos da identidade nacional (NOGUEIRA, 2009). O Baile Perfumado ilustra, na segunda metade da década de 1990, o Cinema da Retomada. Filmes como "Amarelo Manga" (2002, diretor Cláudio Assis) e "Cinema, Aspirinas ${ }^{\circledR}$ e Urubus" (2005, diretor Marcelo Gomes) figuram em listas dos melhores filmes brasileiros daquela década. O filme de Marcelo Gomes ganhou o Prêmio da Educação Nacional, do ministério da educação do governo francês, concedido durante o festival de Cannes de 2005. Já as produções recentes como Aquarius (2016), indicado à Palma de Ouro em Cannes e Bacurau (2019), vencedor do Prêmio do Júri no festival de Cannes, têm obtido destaque internacional.

\section{Trilha metodológica}

\subsection{Os pressupostos da pesquisa}

O presente estudo se vincula com os Estudos Culturais (EC) como âncora epistemológica, atrelando o contexto sócio-histórico e o desenvolvimento de uma abordagem construcionista, que demarca a centralidade da linguagem na construção do mundo social. Para tanto, utilizamos o Circuito da Cultura de Du Gay et al. (2013) como um arcabouço teórico-metodológico. Nesse sentido, o campo dos EC é considerado "[...] não apenas como uma construção teórica, mas como um método de análise adequado para as pesquisas em cultura das mídias, que vislumbra no Circuito da Cultura um protocolo analítico" (LISBOA FILHO; MORAES, 2014, p. 83).

Foi utilizada a análise do foucaultiana do discurso, uma vez que Du Gay $(1996,2000$, 2004) incorpora a discursividade presente em obras de Michel Foucault ao debate sobre as organizações no que concerne à produção de significados e de subjetividades. Assim, Du Gay (1996) realça as estruturas de poder e o papel do discurso como "espaço" para a formação de sujeitos (FOUCAULT, 2005, 2012). Seguindo as orientações de Maingueneau (1998) e Charaudeau e Maingueneau (2004), foram identificadas problemáticas cuja análise demandou o emprego das seguintes categorias: posicionamento e campo discursivo.

O posicionamento está relacionado com o emprego de palavras, vocabulários, e construções por meio do qual um sujeito indica como ele se localiza num espaço discursivo, [de]marcando sua identidade em relação às demais posições de sujeito existentes no interior de um dado campo discursivo. Já a noção de campo discursivo partilha do princípio da importância do interdiscurso sobre o discurso. "O campo discursivo não é uma estrutura estática, mas um jogo de equilíbrio instável” (CHARAUDEAU; MAINGUENEAU, 2004, p. 92), isto é, ele representa um conjunto dos discursos que interagem em dado contexto, no interior dos quais formações discursivas e/ou posicionamentos discursivos que estão em relação de constante embate.

A coleta dos dados consistiu em seis entrevistas semi-estruturadas, realizadas com produtoras cinematográficas sediadas na cidade do Recife. A escolha dos empreendedores culturais se deu por meio de uma pesquisa exploratória com elaboração de um mapeamento com 54 produtoras de audiovisual de Pernambuco focadas na produção de filmes. A redução do número final de entrevistados deu-se por conta da dificuldade de acessar os atores do campo. Num segundo momento, as entrevistas semi-estruturadas foram transcritas e preparadas para o trabalho de análise dos dados. Para cada entrevistado, criamos uma sigla 
contendo as suas iniciais. Em suma, as siglas JJ, RP, MC, MP, PS e CC, representam os respectivos empreendedores culturais na condição de produtores culturais fílmicos.

\section{Análise de dados}

A análise dos dados segue duas dimensões que orientam a ação do empreendedor cultural: a privada e a pública. No decorrer da análise, podemos agrupar sob cada dimensão as duas categorias analíticas do discurso: posicionamento e campo discursivo. Nesse sentido, a dimensão privada e o posicionamento discursivo se relacionam com os momentos do Circuito da Cultura que dialoga ora com o protagonismo do sujeito, ora com a força das estruturas que delimitam sua ação. Na segunda parte, discutiremos os resultados referentes aos momentos da regulação e da representação na dimensão pública e a formação de um campo discursivo.

\subsection{A Dimensão privada e o posicionamento discursivo}

Aqui são discutidos os momentos do consumo, da identidade e da produção - que integram a dimensão privada e se articulam com os posicionamentos discursivos.

\subsubsection{O momento do consumo}

O olhar sobre o momento do consumo dos filmes produzidos em Pernambuco revela as dificuldades de se ampliar o número de espectadores dos filmes e a inserção das obras no circuito de exibição. Assim, destacamos três discursos: o da formação de plateia, o da inserção em circuitos alternativos e o da postura contra a dominação da linguagem televisiva.

Quanto ao discurso da formação de plateia, o efeito alcançado nesse momento compete à busca pela ampliação de público para os filmes locais. Esse desafio pode ser compreendido como resultado da dificuldade de obras "não comerciais" se inserirem no mercado de exibição e alcançarem uma parcela maior de público, como ilustrado a seguir:

“antes de 'O Som ao Redor' que eu me lembro foi o 'Cinema, Aspirinas e Urubus' que fez em torno de 200 a 250 mil pagantes" [..] a realidade dos filmes é que 300 mil pagantes é quase uma utopia, assim, você tem 5 mil pagantes, as vezes mil pagantes” (MP).

"tem um projeto de exibição de curtas metragens no sertão, que se chama 'Cinema volante luar do sertão', que aí a gente exibe no sertão, dessa vez vai pro Sertão do Pajeú, tá na terceira edição já do projeto” (CC).

Os extratos registrados esclarecem que a ampliação do público demanda esforços na busca por formas e canais diferentes para viabilizar a exibição/o consumo dos filmes, uma deles é ampliar as possibilidades de as pessoas assistirem seus filmes como tentativa de fortalecer o discurso da inserção em circuitos alternativos para os filmes produzidos em Pernambuco (SILVA, 2010). Abaixo, estão elucidações da busca por esses circuitos alternativos.

\footnotetext{
"eu quando pensei em fazer uma home page eu fiz num formato simples num site de compartilhamento grátis e tal..." (PS).

"esse filme foi também distribuído na revista Continente que tem uma tiragem de 5 mil exemplares. Ela tem uma circulação apenas em Pernambuco, mas a gente encartou o filmes e mais 3 curtas, dentro da revista tem uma matéria sobre o filme e era uma forma do filme chegar diretamente na casa das pessoas" (MP).
}

O momento do consumo é articulado com o discurso da postura contra a dominação da linguagem televisiva. No contexto do cinema brasileiro, a influência da estética televisiva 
é uma problema para os filmes autorais que não possuem uma linguagem associada a comédias ou dramas que apelam para famosos dos programas televisivos.

\subsubsection{O momento da identidade}

A busca por fixação de uma identidade relacionada com os produtores fílmicos locais se articula com três discursos: as diferentes perspectivas de narração, as parcerias e a profissionalização. As diferentes perspectivas de narração assumem a postura contrária à dominação da mais linguagem televisiva (FIGUEIRÔA, 2006). O momento atual vai além desse rótulo ao contemplar as diferenças entre gerações, entre estilos narrativos e tipos de filmes, conforme aclaram os recortes a seguir:

"e que tem uma proposta de linguagem que se diferencia do blockbuster ou do cinema narrativo nacional" [...] acaba sufocando outras possibilidades, outros olhares, outras linguagens, outras formas de fazer filme que não são da ordem do espetáculo ou do entretenimento" (MP).

$\mathrm{O}$ discurso da parcerias contempla o estabelecimento de redes voltadas para a execução dos projetos vinculados às suas produtoras, típico da economia criativa (GUNDOLF, JOAUEN e GAST, 2018; ROCHA et al, 2018) e indicam vínculos afetivos entre os produtores e outros realizadores e/ou membros da equipe (NOGUEIRA, 2009; SALDANHA, 2009). Os recortes ilustram o efeito do estabelecimento suas de redes formais e informais:

"Eu tenho de certa forma, pode se dizer uma rede informal assim que eu mesmo criei que a empresa mesmo criou” (PS).

"Aí a gente vai conhecendo as pessoas e as pessoas vão se interessando pelo nosso trabalho e gostam do filme, aí a rede vai se formando" $(R P)$.

$\mathrm{O}$ discurso da identidade desses produtores diz respeito à profissionalização, dimensão também debatida nos estudos de Hasumann (2010). A formação de um perfil profissional específico fortalece e legitima a posição do produtor de cinema como agente articulador na produção de filmes, como empreendedor cultural realizador de projetos:

"O produtor executivo não é contador, o produtor executivo não é prestador de contas, ele pode inclusive fazer isso na falta de alguém, mas não seria sua função" [...] O produtor executivo ele é o gestor de um projeto. Ele é o estrategista, aquele que vai planejar, vai ver as melhores opções, desenhar o ciclo de vida, ou prever esse ciclo de vida do projeto ou do produto com base nas informações formais e informais" (MC).

A tensão entre identidade e diferença elucida o fato de o talento individual integrar a elaboração dos projetos artísticos, mas depende do esforço coletivo para assegurar a efetivação de tais projetos e a resultante viabilização dos filmes.

\subsubsection{O momento da produção}

O momento da produção realça o discurso da profissionalização - relacionado ao fortalecimento do setor da produção cultural, à criação de postos de trabalho e à reconfiguração do mercado em torno de projetos sustentáveis (PARKER, 2006; MOON e SONG, 2015). O primeiro efeito desse discurso no campo da produção tange ao desenvolvimento do aparato organizativo das produtoras para responder a mecanismos contratuais de prestação de contas e de comercialização de filmes, conforme ilustrado nas passagens a seguir: 
"nosso modelo de gestão envolve os três sócios, cada um deles tem uma área de atuação" [...] a gente nomeou isso daqui como um colegiado, onde essas 6 pessoas têm uma relação mais horizontalizada e discutem mais os projetos e as decisões que cabem à empresa" (JJ).

"a gente tem um assistente que trabalha diariamente vendendo filmes... deixando a parte legal da empresa ok, é... fazendo inscrições em festivais, enviando filmes. Essa coisa do dia-dia mesmo" (RP).

O segundo efeito encontrado foi o da ampliação da atuação das produtoras, que demonstra o fato de seus dirigentes não se posicionarem apenas como criadores de filmes, mas também de outros produtos audiovisuais, a exemplo dos projetos para televisão (RAVASSI; RINDOVA, 2013; SMITS, 2016).

$\mathrm{O}$ acesso aos mecanismos de produção indica o posicionamento de uma geração de empreendedores estabelecidos na criação e elaboração dos filmes por meio da mobilização contínua de capitais (SCOTT, 2012), o que transforma a produção de cinema em uma atividade fim. Além disso, a centralização da tomada de decisão é vista como uma tendência do produtor no sentido de participar de todos os momentos da sua empresa a fim de garantir os níveis de qualidade dos projetos e se relaciona com os produtores assumirem posição de liderança com os projetos (FLETCHER, 2006). Essa tendência à centralização aparece nos extratos abaixo:

\footnotetext{
"Moderadamente concentrada. Porque com essas pessoas que a gente trabalha, nós acabamos dividindo as decisões" (MC).

"De qualquer forma quando eu recebo algum roteiro ou algum material, eu apresento para o grupo [...] Mas acaba, tipo, é da cultura do capitalismo que os sócios têm uma autonomia maior" (JJ).

"Somos nós dois que damos diretriz total da empresa, porque as grandes decisões somos nós que tomamos" (RP).
}

A finalidade/função expressa que cada integrante ou etapa do processo de produção está vinculado a uma lógica instrumental necessária para o desenvolvimento dos filmes produzidos. Nesse sentido, a orientação para resultados e a otimização de esforços se relacionam com a composição das equipes. Portanto, o componente artístico do projeto demarca a excelência na gestão desses empreendedores (ELLMEIER, 2007; GUNDOLF, JAOUEN; GAST, 2018). A seguir, os relatos ilustram esse aspecto.

"Nós contratamos profissionais de acordo com a nossa necessidade. [no caso o produtor executivo] ... São pessoas que não são artistas, são realmente ligadas a business, a negócios [...] Então ele entraria nesse sentido" (RP).

"Às vezes eu busco um parceiro que ele seja financeiro ou parceiro que tenha uma característica mais técnica" (JJ).

Os mecanismos adaptados de controle revelam a necessidade de organizar e utilizar os recursos necessários à realização do filme com resultados efetivos, de maneira orgânica e adaptada ao contexto daquela produção cultural (KLAMER, 2011; PELTONIEMI, 2015). No entanto, o volume de recursos e de ferramentas de prestação de contas dos órgãos de fomento exige que essa produção cumpra com os editais de produção dos filmes:

"Porque depende da decisão, depende do que a gente está falando, uma decisão de projeto ela tem que ser centrada no projeto e nos controles formais, embora eu ache que todas as decisões nesse sentido ela é influenciada pelos controles informais" (MC). 
A organização das produtoras está pautada pela relação entre projetos/recursos como marcador de sobrevivência. Esse discurso é recorrente quando entre os produtores quanto ao funcionamento de suas empresas e se vinculam ao avanço de modelos alternativos de gestão organizacional, a exemplo da própria gestão por projetos (MOON e SONG, 2015).

O desafio da viabilização comercial dos filmes diz respeito à sustentabilidade das produtoras para além dos projetos audiovisuais em si ou das dotações de editais, algo imperativo na competição por recursos viabilizadores dos filmes, conforme ilustrado a seguir:

"do que em financiamentos e estruturas de fomento que te dêem condições de você passar a uma outra etapa que seria se sustentar, ter capital de giro pra se sustentar [...] essa é uma dificuldade, esse entendimento da lógica das produtoras entrarem na lógica de mercado de sustentabilidade" (MC).

"Quer dizer, isso gera uma demanda maior pro mercado, é uma coisa que vai se alimentando, né? É um ciclo que vai se alimentando. O que é um curso de cinema se não tem trabalho pra fazer quando sair?" (CC).

O agenciamento público se revela como eixo de debate acerca do fomento à produção de cinema. Esse discurso é compartilhado também com o momento da Regulação e será retomado adiante, na respectiva apresentação desse elemento de discussão (seção 5.2.1). Uma perspectiva orientada por resultados econômicos, embora percebida como necessária pelo Empreendedor cultural, o que contrasta com a perspectiva calcada tão-somente em valores estéticos e artísticos caracterizadas pelo universo da cultura (LAMPEL e GERMAIN, 2016; ORIHUELA-GALLARDO et al, 2018).

\subsection{A dimensão pública e o campo discursivo}

A segunda parte desta seção aborda os momentos da regulação e da representação articulados com a construção do campo discursivo emergente no campo de atuação dos produtores entrevistados. O campo discursivo está relacionado com a dimensão pública que orienta a ação do empreendedor cultural.

\subsubsection{O momento da regulação}

O momento da regulação tem interface como o agenciamento público, ou seja, os efeitos da burocratização e da dependência. O ajustamento dos mecanismos e processos referentes à ampliação do fomento por parte do Estado gerou uma estruturação do setor voltada para cumprir as "regras do jogo" impostas pelo poder público no tocante à política cultural no Brasil (ARRUDA, 2003). Aparecem aqui os efeitos da burocratização do fomento quando os produtores constroem uma estrutura organizacional direcionada para responder às normas impostas pelo Estado (BOLAÑO, 2003). O recortes a seguir tratam da burocratização: "o produtor executivo precisa saber é legislação audiovisual, porque como a gente trabalha muito com renúncia fiscal o produtor tem que conhecer muito sobre a legislação audiovisual [...] Mas legislação do audiovisual, se você trabalha com renúncia fiscal, você não pode fazer besteira se não você não faz um segundo projeto [...] porque as regras são muito rígidas para utilização do dinheiro da renúncia fiscal" (JJ).

O efeito dependência revela o posicionamento a favor do fomento público, ora por conta dos mecanismos de controle e governança, ora por conta da falta de interesse da iniciativa privada em investir nesses projetos. Abaixo alguns recortes que elucidam esse efeito: 
"Porque mesmo quando é uma empresa privada, ela normalmente está fomentando por renúncia fiscal. É muito raro que ela faça um marketing direto, então acaba sendo público" (JJ).

"E os editais de financiamento são $100 \%$ públicos" (PS).

"Mas sem isso aí [editais públicos de fomento] a movimentação de trabalho na produtora cairia pela metade" (CC).

O imperativo mercadológico associado ao avanço dos conglomerados de mídia no setor de exibição ou da televisão brasileira expande os produtos para a sala de cinema e demanda do produtor o desenvolvimento de estratégias para superar tais barreiras, em que se encontram o talento artístico e as regras do mercado (LAMPEL e GERMAIN, 2016).

"a gente tá com poucos distribuidores no Brasil e todos são meio que multinacionais, então eles vão privilegiar filmes que tem o formato americano, que não é o nosso. [...] É praticamente exigência do mercado isso." (RP)

"É que o circuito exibidor de cinema está cada vez mais voltado para interesses mercantis [...] é uma janela que está aberta para filmes que sejam comercialmente rentáveis" (MP).

Existe o discurso da dificuldade de driblar os gargalos da circulação quanto aos números de espectadores e à dificuldade de algumas produtoras gerarem um ciclo sustentável de suas produções com as bilheterias na distribuição dos filmes:

"[...] mas a distribuição e o fato das pessoas não conseguirem ver os filmes é o grande tormento de quem faz filme no Brasil atualmente" (MP).

O discurso do impacto tecnológico sugere que a articulação dos produtores possa impulsionar a produção e circulação dos filmes e contribui para a readequação de forças no tocante à organização do setor, em que se busca introduzir técnicas criativas e inovadoras para dinamizar a produção cultural (SUNG, 2015):

"Primeiro você teve a migração de uma plataforma que era antes do cinema na película para o cinema digital [...] o cinema digital é uma realidade que veio para baratear os custos de produção" [...] A internet nós temos usado muito, nossos curtas, uns 5 curtas que a gente fez, todos já foram disponibilizados na internet depois de fazerem a carreira de festivais" (MP).

\subsubsection{O momento da representação}

As representações dos produtores contribuem para compreendermos como esses eles significam sua atuação com destaque para seus diferentes estilos de produção. Há uma vocação à pluralidade de estilos e condições de produção entre si e a busca por distinção com produtores localizados em outros centros de produção cinematográfica mais famosos, a exemplo do eixo Rio-São Paulo, o que demarca características próprias desse grupo de produtores (BELTRÁN e MIGUEL, 2014), como ilustram os recortes a seguir:

"Existem muitos cineastas no Brasil, pessoas assim, mais inteligentes que querem fazer um filme pro público, mas não querem fazer nesse modelo americano" $(R P)$.

"Esse incentivo fiscal não é suficiente pra todo mundo, até porque a maioria das empresas do Nordeste tem uma série de descontos e de isenções porque estão se instalando no Nordeste, então isso é uma dificuldade pra gente captar via incentivo federal aqui no Nordeste. Se você olhar os percentuais de captação de recursos nesta área do setor de audiovisual na lei Rouanet, cerca de $80 \%$ estão no Sul e Sudeste, então essa é outra dificuldade" (MC). 
No momento da representação emerge o discurso que destaca a distinção entre artista e produtor. Essa representação aponta para a posição a ser ocupada pelo produtor além da necessidade uma formação atualizada desse produtor cultural (CAREY E NAUDIN,2006). Assim, a representação de tal posição constitui um dos elos primordiais da produção de cinema que se expressa quando afirmam:

"É a gente escreve edital, fazemos essa parte toda de orçamento tudo isso, mas nós somos artistas, então talvez uma pessoa de administração já pode pensar outras formas de conseguir esse recurso" (RP).

O terceiro discurso emergente versa sobre a formação de plateia, discurso compartilhado com o momento do consumo. Os efeitos desse discurso no tocante à representação tratam da necessidade da requalificação do público e da dificuldade de aproximação com o público, esses efeitos demandam que os produtores, na condição de empreendedores culturais busquem ações criativas para encontrar oportunidades no mercado (GUERRA, PAIVA JÚNIOR, 2011), conforme elucida o trecho a seguir:

"Na minha opinião, para o público voltar a se interessar pelos filmes é preciso formar o espectador, requalificar a audiência, estimular o público a buscar um modelo de cinema que não seja apenas mercadológico, que não seja um entendimento de cinema apenas como entretenimento. [...] Então seria preciso despertar dentro da nossa formação, enquanto cidadão, um olhar crítico para a imagem, pois vivemos em um mundo de imagens" (MP).

A emergência do efeito dificuldade de aproximação com o público indica que o campo discursivo é formado por discursos e interdiscursos que colocam os filmes produzidos no Estado de Pernambuco como produtos de difícil assimilação por parte do grande público. Tais filmes esbarram em barreiras críticas para se viabilizarem nos circuitos de exibição mais próximos da sociedade e terminam sendo tratados como filmes de nicho mesmo na cidade e no Estado onde muitos deles foram produzidos, conforme indicado no estudo de Silva (2010). Os recortes abaixo revelam essa representação:

"Os filmes independentes que não tem atores famosos, que não tem diretores famosos e que tem uma proposta de linguagem que se diferencia do blockbuster ou do cinema narrativo nacional, não tem espaço" (MP).[...] "Eles (grandes players do setor de distribuição) não aceitam os nossos trabalhos e a gente fica meio sem pai e nem mãe. [...] Por isso que agora nossa empresa é distribuidora, a gente agora pode entrar no edital de distribuição sem depender de ninguém e a gente vai criando os mecanismos pra ir, enfim." (RP)

Os efeitos do discurso formação de plateia se expressam também no discurso da invisibilização frente ao mercado, uma vez que os filmes que dificilmente fazem público expressivo nas bilheterias conseguem acessar patrocínios e investidores para a realização da obra. As possíveis parcerias ou formatos de inserção das obras junto a produtos ou empresas locais são formas de ativação da marca e constituem novas oportunidades de inserção no mercado (ELMEIER, 2007). Tal invisibilização sustenta a dependência dos produtores frente ao fomento público:

"É uma pena que os empresários ainda não atentaram para grande força que o cinema é né?" (RP).[...]"Enquanto não temos uma política pública maior que permita que a gente vire a mesa e retome o espaço que perdeu pro cinema comercial a gente vai caminhando dessa forma" (MP).[...] "Terceiro, eu acho que falta compreensão dos agentes privados, 
financiadores, do quanto é interessante investir nessa área porque são projetos de média e longa duração" (MC).

Uma das formas mais comuns de representar a produção de filmes produzidos por empreendedores culturais que atuam em Pernambuco reside em destacar o reconhecimento do mérito dessas obras nos circuitos de festivais nacionais e internacionais e junto à crítica especializada. $\mathrm{O}$ discurso do filme premiado e bem visto pelos olhos da crítica especializada contribui para que os filmes locais consigam ter espaço midiático, conseguindo se inserir na mídia de massa, mas não é suficiente para conquistar e alavancar o público. Dessa forma, o discurso do reconhecimento/mérito poderia ser mais bem articulado a fim de contribuir para a ampliação de público e/ou a alcance da distribuição desses filmes, além de gerar valor agregado para o filme (RAVASSI; RINDOVA, 2013) . Os recortes seguir realçam a relevância desses prêmios:

"Porque a gente tá levando o cinema pernambucano pra longe, muito longe [...] o governador (o ex-governador Eduardo Campos) sabe disso, tanto que ele tá investindo tanto. Porque o nome de Pernambuco tá indo pra além do Brasil, festivais como Rotterdam, Cannes, Cannes eu já participei também com um filme. [...] São lançados em festivais então posso dizer que o mundo todo, teve filme da gente que foi pro Egito, Estados Unidos, diversos lugares" (RP)."[...] isso porque o filme foi indicado ao Oscar pelo Brasil, então ele fez uma primeira leva na casa dos 100 mil e depois que foi indicado ao Oscar ele voltou aos cinemas e deu uma turbinada" (MP).

Por fim, destaca-se o discurso acerca da tipicidade do setor de atuação, construção da representação de que o campo da produção de cinema possui características próprias que culminam na existência e permanência de práticas organizacionais associadas ao "modo como as coisas são feitas". Tal tipicidade impacta na emergência de discursos que posicionam a ação do empreendedor cultural, a exemplo da profissionalização (perfil profissional específico), dos mecanismos adaptados de controle e das novas possibilidades de distribuir os filmes. Nesse sentido, analisar o empreendedorismo cultural no campo do cinema resulta na compreensão acerca do modo como o produtor cultural mobiliza seus saberes em torno da elaboração dos filmes, superando barreiras mercadológicas e se adaptando às oportunidades do ambiente no qual atua (ROCHA et al, 2018). Apresentamos os trechos a seguir, representativos acerca desses elementos indutores ao empreendedorismo:

"É tudo muito conjuntural na economia da cultura, nunca é uma coisa. É sempre uma série de fatores" (MC).

"(o produtor de cinema) também é uma profissão criativa, ele tem que criar mecanismos pra gerar possibilidades" (RP).

"são mecanismos que nós estamos tentando desenvolver para justamente furar esse bloqueio e tentar levar um olhar mais aguçado" (MP).

O Circuito da Cultura, portanto, na condição epistemológica de marco teóricometodológico do estudo possibilita a análise da ação empreendedora sob uma perspectiva multifacetada, destacando o fato de que a orientação da ação empreendedora no campo da produção cultural não se restringe a aspectos tão somente gerenciais, conforme os estudos de Lima (2014) e Lisboa Filho e Moraes (2014). Nesse sentido, o fenômeno demanda do empreendedor certa ação reflexiva a fim de garantir sua inserção em um segmento profissional no qual atue junto a diferentes atores e que contemple funções diversificadas.

A Figura 1 destaca o fato de que articulação discursiva que orienta a ação dos produtores de cinema atuantes em Pernambuco incorpora a seu modo a lógica circular e de 
múltipla determinação encontrada no modelo do Circuito da Cultura. Podemos observar discursos e efeitos compartilhados em diferentes momentos e a construção de um campo discursivo que sustenta o posicionamento dos empreendedores culturais no tocante à busca por novas formas de produzir suas obras e fazê-las circular na sociedade. Os momentos Produção, Consumo e Identidade estão assinalados na cor cinza, pois demarcam a influência do posicionamento discursivo no tocante à atuação e ao protagonismo dos sujeitos nesses momentos. Ao lado dos momentos da Regulação e da Representação eles compõem o campo discursivo mais amplo que foi revelado pela análise deste estudo. As linhas tracejadas utilizadas foram inseridas nessa figura para separar graficamente os discursos e os efeitos emergentes em cada momento, mas que não representam a ideia de um limite rígido entre tais momentos. Nesse sentido, concluímos nossa análise tendo como eixo de discussão o aspecto da circularidade proveniente do Circuito da Cultura utilizado como marcador teóricometodológico da prática empreendedora cultural.

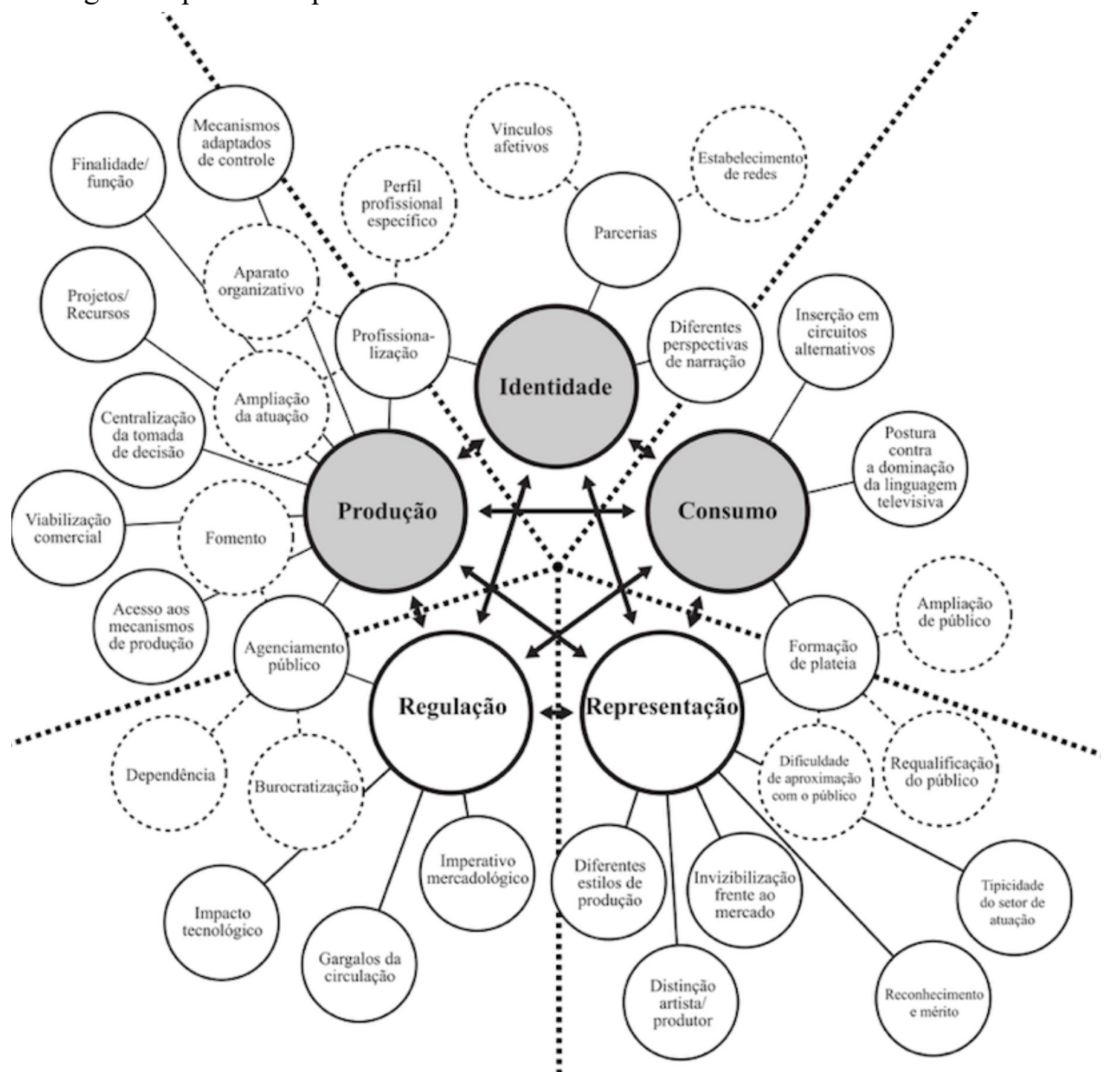

Figura 1 - Mapa analítico do estudo acerca do Empreendedorismo Cultural no campo do cinema Fonte: Elaboração própria (2019). 
A utilização do Circuito da Cultural possibilita, portanto, a análise da ação empreendedora sob uma perspectiva multifacetada, destacando o fato de que a orientação da ação empreendedora no campo da produção cultural não deve ficar restrita a aspectos gerenciais apenas, de acordo com o debate contido nos estudos de Lima (2014) e Lisboa Filho e Moraes (2014). Nesse sentido, o destaque ao Empreendedorismo Cultural demanda do sujeito empreendedor uma ação e uma aprendizagem ampla a fim de contemplar sua inserção em um segmento profissional no qual ele irá atuar junto a diferentes atores e funções.

\section{Considerações finais}

Como forma de destacar aspectos conclusivos emergentes na análise deste estudo, voltamos à indagação inicial como questão norteadora da tese: Como ocorre o Empreendedorismo Cultural no campo da produção de filmes em Pernambuco?

É imperativo se ter em mente a conexão entre o produto cultural e a subjetividade daquele ator que o cria e desenvolve artefatos simbólicos no seu cotidiano profissional, em que se reconhece aqui o protagonismo do empreendedor cultural. A ação de tal empreendedor no campo da produção de filmes está relacionada ao esforço de emancipação de grupos profissionais intensivos em criatividade e à melhoria de condições de absorção de recursos em meio à articulação com os seus parceiros estratégicos. Logo, o perfil de atuação do empreendedor cultural nos remete a (re)discutir os conceitos de competição e estratégia organizacional sob a perspectiva de um setor produtivo caracterizado pela agregação de pessoas em torno de projetos inovadores que expressam aspectos subjetivos de seus produtores imersos na elaboração de bens simbólicos e artísticos.

A criação do bem simbólico se contrapõe ao entendimento da visão reativa e unidirecional de estratégias tradicionais orientadas para o mercado. Isso também desestabiliza a lógica utilitarista vigente no olhar sobre o fenômeno empreendedor clássico e sugere uma abertura da compreensão acerca da ação empreendedora em favor de uma abordagem multidimensional e dialógica. Portanto, o estudo busca trazer luz a respeito do entendimento do empreendedorismo cultural cinematográfico no que concerne a meios de distribuição e exibição dos filmes, a elementos estéticos dessa produção artística e às práticas gerenciais inerentes ao esforço empresarial para o alcance de êxito efetivo dos filmes exibidos junto ao público.

A ação dos produtores culturais analisados indica a sobreposição do indivíduo com o aparato institucional do setor, repercutindo na geração e distribuição de capital por meio do fortalecimento de seus relacionamentos e da mobilização dos agentes envolvidos na produção dos bens culturais. Nesse sentido, avançamos com a discussão acerca da produção cultural, ao lançarmos luz sobre os aspectos centrais emergentes dessa ação no contexto da produção de cinema, a exemplo da busca pela profissionalização daquele tipo de empreendedor e sua equipe e da construção de redes e parcerias pautadas nas relações de confiança e cooperação.

Para os produtores, parece crucial pensar no aprimoramento da sua atuação profissional para além do momento da produção, assim como, existe a necessidade crescente de se buscar alternativas para a circulação dos filmes. Para os formuladores de políticas públicas voltadas para o cinema, destacamos a necessidade de ampliação do escopo de tais 
políticas no tocante do fomento de novas formas de distribuição e exibição dos filmes. Destacamos ainda que é preciso garantir a manutenção das políticas de fomento à produção de cinema, incluindo o incentivo ao desenvolvimento de projetos de empreendedorismo fílmico voltados para outras janelas de exibição, a exemplo da Internet e da televisão.

O estudo se limita por abranger empiricamente a produção local de filmes independentes inserida no contexto pernambucano. Dessa forma, futuros estudos poderiam investigar diferentes pólos produtivos de fora do mainstream da produção audiovisual brasileira a fim de ampliar o debate acadêmico no âmbito de práticas empreendedoras que protagonizam produções culturais contra-hegemônicas no universo da economia criativa. Nesse sentido a análise do discurso pode oferecer aparato teórico-metodológico pertinente na busca por uma profícua construção de conhecimento acerca do empreendedorismo cultural. Ademais, emerge a possibilidade de se investigar a dinâmica interna da ação do empreendedor cultural relacionada com os pontos do Circuito da Cultura no tocante às características próprias do consumo, da identidade, da representação e da regulação. Outro desafio investigativo reside na necessidade de se ampliar e diversificar o número de atores das pesquisa a fim de garantir a magnitude da análise de dados no tocante às experiências relativas ao empreendedorismo na esfera da cultura.

A ação coletiva dos empreendedores culturais intermedia o processo de [re]apropriação reflexiva do uso de novas ferramentas gerenciais e técnicas de organização, o que possibilita a inserção desses atores no contexto da produção cultural com alto valor simbólico. Esse valor passa a ser constituído a partir das identidades dos produtores e realizadores e por meio do trabalho associativo, gerando um processo capaz de causar rupturas no modus operandi da produção, da circulação e do consumo de bens simbólicos.

\section{Referências}

ARRUDA, M. A. do N. A Política Cultural: regulação estatal e mecenato privado. Tempo Social, v.15, n. .2, nov., 2003, p. 177-193.

BANKS, M.; LOVATT, A.; O'CONNOR, J.; RAFFO, C. Risk and Trust in the Cultural Industries. Geoforum. v. 31, n. 4, p. 453-464, 2000.

BELTRÁN, G. J.; MIGUEL, P. Doing culture, doing business: a new entrepreneurial spirit in the Argentine creative industries. International Journal of Cultural Studies. v. 17, n. 1, p. 39-54, 2014.

BerTelli, A. M.; CONNOLly, J. M.; MASON, D. P.; CONOVER, L. C. Politics, management, and the allocation of arts funding: evidence from public support for the arts in the UK. International Journal of Cultural Policy, v. 20, n. 3, p. 341-359, 2014.

BOLAÑO, C. Da derivação à regulação: para uma abordagem da Indústria Cultural. Revista de Economía Política de las Tecnologías de la Información y Comunicación, v. 5, n.3, set./dez. p. 6t0-96, 2003.

CALÁS, M.; SMIRCICH, L.; BOURNE, K. Extending the boundaries: reframing "Entrepreneurship as Social Change" through feminist perspectives. Academy of Management Review, v. 34, n. 3, p. 552-69, 2009.

CHARAUDEAU, P.; MAINGUENEAU, D. Dicionário de análise do discurso. São Paulo: Contexto, 2004.

CUNHA FILHO, P. C. Apresentação. In. (org.) Relembrando o Cinema 
Pernambucano: dos arquivos de Jota Soares. Recife: Editora Massangana, 2006, p. 7-13.

CUNHA FILHO, P. C. A Utopia Provinciana: Recife, Cinema, Melancolia. Recife: Editora Universitária da UFPE, 2010.

DAVEL, E.; CORA, M. A. J. Empreendedorismo Cultural: cultura como discurso, criação e consumo simbólico. Políticas Culturais em Revista, v. 9, n. 1, p. 363, 2017.

DRUCKER, P. F. Inovação e Espírito Empreendedor: práticas e princípios. 7. ed. São Paulo, Editora Cengage Learning, 2008.

DU GAY, P. Consumption and Identity at Work. Londres: Sage, 1996.

DU GAY, P. In Praise of Bureaucracy: Weber, Organization, Ethics. Londres: Sage, 2000.

DU GAY, P.Against "Enterprise" (but not against "enterprise", for that would make no sense). Organization, v. 11, n. 1, 2004, p. 37-57.

DU GAY, P.; HALL, S.; JANES, L.; MACKAY, H.; NEGUS, K. Doing Cultural Studies:

The Story of the Sony walkman. 2. ed. Londres: SAGE Publications, 2013.

ELLMEIER, A. Cultural entrepreneurialism: on the changing relationship between the arts, culture and employment. International Journal of Cultural Policy, v. 9, n. 1, p.3-16, 2007.

GUNDOLF, K.; JAOUEN, A.; GAST, J. Motives for strategic alliances in cultural and creative industries. Creativity and Innovation Management, v. 27, n. 2, p. 148-160, 2018.

FIGUEIRÔA, A. Cinema Pernambucano: uma história em ciclos. Recife: Fundação de Cultura Cidade do Recife, 2000.

FIGUEIRÔA, A. O manguebeat cinematográfico de Amarelo Manga: energia e lama nas telas. In: ENCONTRO DOS NÚCLEOS DE PESQUISA DA INTERCOM, 6., 2006, Brasília. Comunicação Audiovisual... Brasília: NP 07, 2006.

FOUCAULT, M. A Arqueologia do Saber. 8. ed. São Paulo: Forense Universitária, 2012.

FOUCAULT, M. A Ordem do Discurso. 9. ed. São Paulo: Edições Loyola, 2005.

GUERRA, J. R. F.; PAIVA JÚNIOR, F. G. Empreendedorismo Cultural na produção cinematográfica: a ação empreendedora de realizadores de filmes pernambucanos. RAI Revista de Administração e Inovação. v. 8, n. 3, jul./set., p. 78-99, 2011.

JULIEN, P. A. Empreendedorismo Regional e Economia do Conhecimento. São Paulo: Saraiva, 2010.

KLAMER, A. Cultural entrepreneurship. The Review of Austrian Economics, v. 24, n. 2, p. 141-156, 2011.

LAMPEL, J.; GERMAIN, O. Creative industries as hubs of new organizational and business practices. Journal of Business Research, v. 69, n. 7, p. 2327-2333, 2016.

LISBOA FILHO, F. F.; MORAES, A. L. C. Estudos Culturais aplicados a pesquisas em mídias audiovisuais: o circuito da cultura como instrumento analítico. Significação - Revista de Cultura Audiovisual. v. 41, n. 42, p. 67-86, p. 2014.

MAINGUENEAU, D. Termos-Chave da Análise do Discurso. Belo Horizonte: Ed. UFMG, 1998.

NOGUEIRA, A. M. C. O novo ciclo de cinema em Pernambuco: a questão do estilo. Recife: Editora da UFPE, 2009.

ORIHUELA-GALLARDO, F.; FERNÁNDEZ-ALLES, M.; RUIZ-NAVARRO, J. The influence of the cultural entrepreneur on the performance of cultural and creative firms. Academia Revista Latinoamericana de Administracion, v. 31, n. 2, p. 392-409, 2018.

PELTONIEMI, M. Cultural industries: Product-market characteristics, management 
challenges and industry dynamics. International Journal of Management Reviews, v. 17, n. 1, p. 41-68, 2015.

ROCHA, D. T. DA; BONFIM, L. R. C.; CITADIN, M. W.; GIMENEZ, F. A. P. Mapeando as relações de coprodução e codistribuição no cinema brasileiro: uma análise pela ótica da teoria de redes. Intercom: Revista Brasileira de Ciências da Comunicação, v. 41, n. 1, p. 41-61, 2018.

SCHUMPETER, J. A. A Teoria do Desenvolvimento Econômico. São Paulo: Abril Cultural, 1982.

SCOTT, M. Cultural entrepreneurs, cultural entrepreneurship: Music producers mobilising and converting Bourdieu's alternative capitals. Poetics, v. 40, n. 3, p. 237-255, 2012.

SILVA, T. T. A produção social da identidade e da diferença. In: (org). Identidade e diferença: a perspectiva dos Estudos Culturais. 8. ed. Petrópolis, RJ: Vozes, 2008, p. 73-102. SMITS, R. Gatekeeping and networking arrangements: Dutch distributors in the film distribution business. Poetics, v. 58, p. 29-42, 2016.

HÉRAUD, J.-A. A New Approach of Innovation: from the Knowledge Economy to the Theory of Creativity Applied to Territorial Development. Journal of the Knowledge Economy, 2016.

MOON, S., \& SONG, R. The Roles of Cultural Elements in International Retailing of Cultural Products: An Application to the Motion Picture Industry. Journal of Retailing, v.91, n.1), p.154-170, 2015.

RAVASSI, D.; RINDOVA, V. Criação de valor simbólico. RIGS - Revisa Interdisciplinar de Gestão Social. v. 2, n. 2, p. 13-35, 2013.

SUNG, T. K. Application of information technology in creative economy: Manufacturing vs. creative industries. Technological Forecasting and Social Change, v. 96, p. 111-120, 2015. Elsevier Inc. Disponível em: <http://dx.doi.org/10.1016/j.techfore.2015.04.002>. 